\title{
In silico, NMR and pharmacological evaluation of an hydroxyoxindole cholinesterase inhibitor
}

\author{
Patrícia Bacalhau $^{\mathrm{a}, \mathrm{b}, \mathrm{c}}$, Luís Fernandes ${ }^{\mathrm{a}, \mathrm{c}}$, M. Rosário Martins ${ }^{\mathrm{a}, \mathrm{b}}$, Fátima Candeias ${ }^{\mathrm{a}}$, \\ Elisabete P. Carreiro ${ }^{\mathrm{c}}$, Óscar López ${ }^{\mathrm{d}}$, A. Teresa Caldeira ${ }^{\mathrm{a}, \mathrm{b}}$, Jane Totobenazara ${ }^{\mathrm{c}}$, Rita C. Guedes ${ }^{\mathrm{e}}$, \\ Anthony J. Burke ${ }^{\mathrm{a}, \mathrm{c}, *}$ \\ ${ }^{a}$ Departamento de Química, Escola de Ciências e Tecnologia, Universidade de Évora, Rua Romão Ramalho 59, 7000-671 Évora, Portugal \\ ${ }^{\mathrm{b}}$ Laboratório HERCULES, Institute for Research and Advanced Studies (IIFA), Universidade de Évora, Palácio do Vimioso, Largo Marquês de Marialva 8, 7000-809 Évora, \\ Portugal \\ ${ }^{\mathrm{c}}$ Centro de Química de Évora, Institute for Research and Advanced Studies (IIFA), Universidade de Évora, Rua Romão Ramalho 59, 7000-671 Évora, Portugal \\ d University of Seville, Faculty of Chemistry, Professor Garcia González Street, 1, 41012 Seville, Spain \\ ${ }^{\mathrm{e}}$ Research Institute for Medicines (iMed.ULisboa), and Department of Medicinal Chemistry, Faculty of Pharmacy, Universidade de Lisboa, Av. Prof. Gama Pinto, 1649-003 \\ Lisbon, Portugal
}

\section{A B S T R A C T}

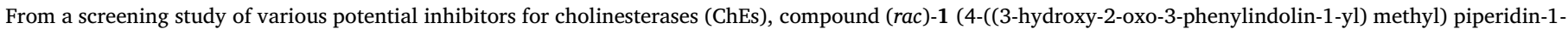

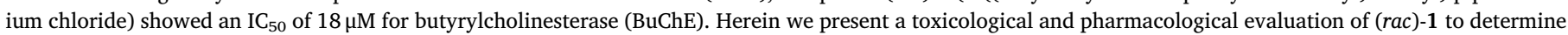

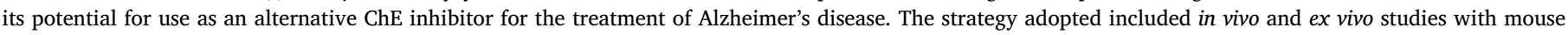
models, Molecular Modelling and Saturation Transfer Difference (STD) NMR studies.

Preliminary molecular docking studies were conducted with both $(R)$ and $(S)-1$ with acetylcholinesterase (AChE) and BuChE, prior to advancing to the mouse

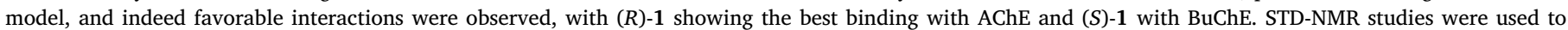

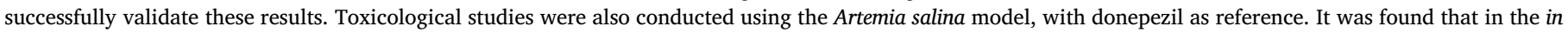

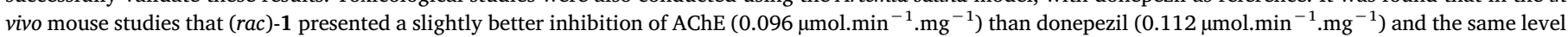
of inhibition for BuChE as donepezil $\left(0.014 \mu \mathrm{mol} . \mathrm{min}^{-1} . \mathrm{mg}^{-1}\right)$.

\section{Introduction}

Alzheimer's disease (AD) is the most common neurodegenerative disease and the most prevalent cause of dementia among the elderly. ${ }^{1,2}$ This irreversible neurological disorder is characterized by memory and cognitive impairment, behavioral and learning deficits., ${ }^{3,4}$ Neuropathologically, $\mathrm{AD}$ is portrayed by the presence of amyloid $\beta$ (A $\beta$ ) plaques and neurofibrillary tangles (NFT) of a phosphorylated form of protein tau. The formation of $A \beta$ plaques and NFTs leads to neurodegeneration and loss of cholinergic neurons in the basal forebrain with consequent reduction of acetylcholine (ACh) levels in the hippocampus and cortex of the brain. ${ }^{5}$ Both acetylcholinesterase (AChE) and butyrylcholinesterase (BuChE) degrade $\mathrm{ACh}$, this is more prevalent for $\mathrm{BuChE}$ in the latter stages of the disease. In order to increase ACh levels, the use of reversible inhibitors of the enzyme acetylcholinesterase (AChE) and butyrylcholinesterase (BuChE) has been one of the prime strategies for controlling the symptoms of $\mathrm{AD} .^{6,7}$ There is no cure for this disease. Nowadays, only three drugs are commercially available as AChE inhibitors for the treatment of AD: galantamine, rivastigmine and donepezil (Fig. 1) and which have different draw-backs. ${ }^{8}$ Given this situation, it is imperative that new and less expensive AChE inhibitors become available for AD treatment.

The hydroxyoxindole scaffold is present in a number of molecules that exhibit diverse pharmacological profiles, that includes anti-cancer, anti-HIV, antioxidant, antibacterial, antidiabetic, AChE/BuChE inhibition, kinase inhibition, vasopressin antagonism, progesterone antagonism, anti-leishmanial, $\beta 3$ adrenergic receptor antagonism, analgesic, spermicidal, phosphatase inhibition, neuroprotection, and $N$-methyl-Daspartate (NMDA) blocker activities. ${ }^{9}$

We have previously reported the design and synthesis of a new family of tertiary 3-hydroxy- and 3-alkoxyoxindole derivatives which presented good AChE and BuChE inhibitory activities. ${ }^{10}$ Some of the key hits (( $r a c)-1$ to ( $r a c)-4)$ that were identified are shown in Fig. 2 with their $\mathrm{IC}_{50}$ values. Our interest then moved to evaluating these compounds in an animal model, and thus the issue of bioavailability was critical. We found that ( $\mathrm{rac}$ )-1 (4-((3-hydroxy-2-oxo-3-phenylindolin-1yl) methyl) piperidin-1-ium chloride) (Fig. 2) gave promising inhibition of BuChE $(18 \mu \mathrm{M})$ (under incubation conditions). In addition, only after

\footnotetext{
*Corresponding author.
} 
<smiles>COc1cc2c(cc1OC)C(=O)C(CC1CCN(Cc3ccccc3)CC1)C2</smiles>

Donepezil<smiles>COc1ccc2c3c1O[C@H](C3)[C@H]1CCN(C)CC=C[C@H]1C2</smiles>

Galantamine<smiles>CCN(C)C(=O)Oc1cccc([C@H](C)N(C)C)c1</smiles>

Rivastigmine

Fig. 1. Current Food and Drug Administration (FDA) - approved drugs for AD (cholinesterase inhibitors).<smiles>O=C1N(CC2CC[NH2+]CC2)c2ccccc2C1(O)c1ccccc1</smiles>

(rac)-1<smiles>O=C1N(CC2CCN(Cc3ccccc3)CC2)c2ccccc2C1(O)c1ccccc1</smiles>

(rac)-2<smiles>O=C1N(Cc2ccccc2)c2ccccc2C1(O)c1ccccc1</smiles>

(rac)-3<smiles>O=C1N(Cc2cccc(Cl)c2)c2ccccc2C1(O)c1ccccc1</smiles>

(rac)-4

$$
\begin{array}{llll}
I_{50}=500.21 \pm 62.01 \mu \mathrm{M}(\mathrm{AChE}) & \mathrm{IC}_{50}=193.09 \pm 10.12 \mu \mathrm{M}(\mathrm{AChE}) & \mathrm{IC}_{50}=237.18 \pm 6.97 \mu \mathrm{M}(\mathrm{AChE}) & \mathrm{IC}_{50}=128.62 \pm 18.48 \mu \mathrm{M}(\mathrm{AChE}) \\
\mathrm{IC}_{50}=18.26 \pm 0.75 \mu \mathrm{M}(\mathrm{BuChE}) & \mathrm{IC}_{50}=6.61 \pm 0.26 \mu \mathrm{M}(\mathrm{BuChE}) & \mathrm{IC}_{50}=7.41 \pm 0.001 \mu \mathrm{M}(\mathrm{BuChE}) & \mathrm{IC}_{50}=1.02 \pm 0.001 \mu \mathrm{M}(\mathrm{BuChE})
\end{array}
$$

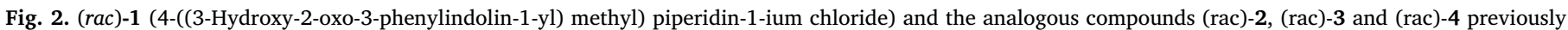
identified as ChE inhibitors. ${ }^{10}$ Results for ( $\mathrm{rac}$ )-1 and (rac)-2 were obtained under incubation conditions.

Table 1

Physicochemical properties. Molecular descriptors calculated by MOE 2018.0101, MW (Molecular Weight), TPSA (Polar surface area $\left.\left(\AA^{2}\right)\right)$, logS $(\log$ of the aqueous solubility mol/L) and $\log \mathrm{P}(\log$ of the octanol/water partition coefficient).

\begin{tabular}{lllll}
\hline Compound & MW & TPSA & logS & $\operatorname{logP}$ \\
\hline (rac) -1 & 323.4 & 57.15 & -3.54 & 2.79 \\
$($ rac $)-2$ & 413.5 & 44.98 & -5.44 & 4.85 \\
$($ rac $)-3$ & 315.4 & 40.54 & -4.94 & 4.16 \\
$($ rac $)-4$ & 349.8 & 40.54 & -5.67 & 4.78 \\
\hline
\end{tabular}

conclusion of our bioassays did we develop a robust asymmetric route to $(\mathrm{rac})-4^{10}$ which eventually can also be used to access both enantiomers of $(\mathrm{rac})-\mathbf{1}$ for further pre-clinical pharmacological evaluations. Due to its favorable solubility and physico-chemical properties (see discussion below), (rac)-1 was chosen for further pharmacological evaluation. Herein we present a toxicological and pharmacological evaluation of (rac)- 1, including in vivo and ex vivo studies with mouse models, Molecular Modelling and Saturation Transfer Difference (STD) NMR studies.

\section{Results and discussion}

\subsection{Synthesis of (rac)-1}

Compound ( $\mathrm{rac}$ )-1 was synthesized following our previously published synthetic methodology. ${ }^{10}$ The synthetic procedure comprises a Phenyl-Grignard Nucleophilic Addition at the 3-carbonyl group of the isatin substrate and subsequent microwave assisted $\mathrm{N}$-alkylation at position 1 with 4-( $N$-Boc-piperidinyl)-methylenyl-methylsulfonate. The hydrochloride salt was obtained by deprotection under acidic conditions.

\subsection{Docking analysis with cholinesterases}

Some important physicochemical parameters of relevance for drug design: are MW (Molecular Weight including implicit hydrogens), TPSA (Polar surface area $\left(\AA^{2}\right.$ ) (calculated using group contributions to approximate the polar surface area from connection table information only, parametrization of Ertl et al., ${ }^{11}$ ) solubility (logS, calculated from an atom contribution linear atom type model $^{12}$ ) and lipophilicity (logP, calculated as the log of the octanol/water partition coefficient, this property is calculated from a $\sim 100$ parameter linear atom type model on 1827 molecules $^{13}$ ) were calculated using MOE 2018 descriptors option. ${ }^{14}$ These properties were calculated for compounds ( $\mathrm{rac}$ )-1 (rac)-4 (Table 1).

All the analyzed compounds showed low molecular weights, revealing an interesting potential for derivatization. Both ( $r a c)-1$ and (rac)-3 were the lower MW compounds studied. Also, calculations of TPSA (topological polar surface area), all below $60 \AA^{2}$, suggest that these compounds should be almost completely absorbed.

Since lipophilicity is identified as an important descriptor for CNS penetration we were pleased to observe that the calculated $\log P$ value for ( $\mathrm{rac}$ )-1 was the lowest for all the tested compounds. In fact, Hansch and Leo have proposed that highly lipophilic molecules are partitioned within the lipid interior of the membrane, and thus retained there. ${ }^{15}$ For several classes of CNS active substances, Hansch and Leo found that blood-brain barrier penetration is optimal when the $\log \mathrm{P}$ values are in the range of 1.5-2.7, with the mean value of 2.1 , a value in the same range as that calculated for ( $\mathrm{rac}$ )-1. As a comparison, the mean value for ClogP for some of the marketed CNS drugs is 2.5 .

Solubility of a drug candidate is an important property as it reflects the bioavailability of the compound. Dose formulation is a problem for compounds showing poor solubility. We calculated $\log$ s for the four compounds and we found that ( $\mathrm{rac})-\mathbf{1}$ is the compound with a greatest $\log$ (less negative), i.e. -3.54 . $>80 \%$ of the drugs on the market have a (estimated) $\log$ s value greater than -4 . 
These results clearly indicated that of the 4 compounds described (rac)-1 was the best candidate for animal model studies.

\subsubsection{Ligand interactions with acetylcholinesterase}

Kinetic studies using ( $\mathrm{rac}$ )-1 and eeAChE (Electrophorus electricus (eel)) showed that the inhibition was reversible competitive (see Supporting information), and considering the structural analogy with the other inhibitors, compounds ( $\mathrm{rac}$ )-2 to ( $\mathrm{rac}$ )-4, would be expected to be also competitive inhibitors.

Although the inhibition of $e e \mathrm{AChE}$ by $(\mathrm{rac})-\mathbf{1}$ was shown to be weak $(500 \mu \mathrm{M})$, considering the inherent genomic sequence difference between both eeAChE and $h \mathrm{AChE}$ and $e q \mathrm{BuChE}$ and $h \mathrm{BuChE}^{16}$ it was of interest to conduct some docking studies to gain some insights on the type of binding interactions between the ligand and the enzyme. It should be noted that the docking studies were conducted with both enantiopodes of (rac)-1.

We used the PDB structures 4EY7 (human AChE) and 4TPK (human BuChE) for our docking studies.

In the case of our docking studies with AChE, it was observed that compound ( $S$ )-1 established a H-bond interaction between a hydrogen atom of the ligand's piperidine's protonated amine and Glu202, at a distance of $1.94 \AA$, a $\mathrm{H}-\pi$ interaction between the piperidine ring position 4 hydrogen atom and Trp86, at a distance of $3.09 \AA$, a second $H-\pi$ between the 3-hydroxy group and Phe338, at a distance of $2.89 \AA$ and a $\pi-\pi$ interaction between the 3-phenyl group and Tyr341 at a distance of $3.11 \AA ̊$ (Fig. 3).

Compound (R)-1 establishes two H-bonds, one between the 3-hydroxy group and Asp74, at a distance of $1.94 \AA$, and a second, weaker $H-\pi$ interaction between the 3-phenyl group and Asp74, at a distance of $2.14 \AA$ (Fig. 3). The ligand also establishes two $\mathrm{H}-\pi$ interactions, one between the piperidine ring's protonated amine and Trp86, at a distance of $2.98 \AA$ and a second one between one of the piperidine ring methylene bridge's hydrogen atoms and Phe338, at a distance of $3.34 \AA$ (Fig. 4). A $\pi-\pi$ interaction (hydrophobic interaction) is also established between the ligand's core aromatic ring and Tyr341, at a distance of 3.87 A. Finally, an intramolecular (ligand-ligand) strong H-bond is established between the 2-carbonyl group and one of the piperidine ring's axial hydrogen atoms, locking the piperidine ring in the chair conformation (Fig. 3).

The set of interactions of compound $(R)-\mathbf{1}$ with AChE are translated to a ChemPLP scoring function value of 74.4 , which was higher than that of its enantiopode, thus indicating that in the case of the assays with $(\mathrm{rac})-\mathbf{1}$, it would be this enantiomer that is the strongest binder of the two. To correlate the stability and interaction patterns of Donepezil inside the hAche binding site with ( $r a c)-1$ it was calculated and compared with both enantiomers of $\mathbf{1}$ (it should be noted that Donepezil is prescribed as the racemate, but in these studies we used the $(R)$-enantiomer). These studies revealed that the Donepezil binds exactly in the same region of the AChE binding site as that of $(S)-\mathbf{1}$ and $(R)-\mathbf{1}$, undergoing hydrophobic interactions with Trp86 ( $\pi-\pi$ interaction), and Trp286 ( $\pi-\pi$ interaction), and with Phe295 via a hydrogen bond with the carboxylic oxygen (Fig. 3F). Again, the presence of hydrophobic interactions with Trp86 is essential for the inhibitory activity.

It should be noted that we have previously conducted docking studies with ( $\mathrm{rac}$ )-2 using crystal structures of human AChE at $2.35 \AA$ (PDB code 4EY7) and human BuChE at $2.10 \AA$ (PDB code $4 \mathrm{BDS}),{ }^{10}$ and the results showed that Trp86 manifested a hydrophobic interaction with the oxindole group and Phe338 showed a key hydrophobic interaction with the benzyl group, which was expected in this case.

\subsubsection{Ligand interactions with butyrylcholinesterase}

Kinetic studies using ( $\mathrm{rac}$ )-1 and eqBuChE (equine) showed that the inhibition was reversible competitive (see Supporting information), and considering the structural analogy with the other compounds, inhibitors ( $\mathrm{rac}$ )-2 to ( $\mathrm{rac}$ )-4, would be expected to be also competitive inhibitors. In fact, the $K_{\mathrm{i}}$ was determined to have a value of
$41 \pm 12 \mu \mathrm{M}$.

Compound ( $S$ )-1 establishes a H-bond between the piperidine ring protonated amine group and Gly116, at a distance of $2.11 \AA$, a $\pi-\pi$ interaction between the 3-phenyl group and Trp82, at a distance of $3.74 \AA$ and a second $\pi-\pi$ interaction between the ligand's core aromatic ring and Tyr332, at a distance of $3.51 \AA$ (Fig. 4).

Compound $(R)-1$ establishes a H-bond between piperidine's protonated amine and Pro285, at a distance of $1.87 \AA$, a second H-bond between the 3-hydroxy group and His438, at a distance of $1.95 \AA$, an $\mathrm{H}-\pi$ interaction between the piperidine ring methylene bridge's hydrogen atom and the Phe329 amino acid residue, at a distance of $3.09 \AA$ and a $\pi-\pi$ interaction between the 3-phenyl group and Trp82 at a distance of $3.30 \AA$ (Fig. 4). The set of interactions simulated here were different from those that were simulated previously for ( $\mathrm{rac}$ )-2, which was probably due to the presence of the benzyl group in ( $\mathrm{rac}$ )-2.

The set of interactions of compound $(R)-1$ with BuChE presented a ChemPLP scoring function value of 60.36. In this case, contrary to $\mathrm{AChE}$, it is (S)-1 that is the better binder. This difference is the result of dissimilarities in the structure of the surface of the ChE active site, the more hydrophobic nature of the BuChE active site surface favors the $S$ enantiomer, whereas, the more aliphatic surface of the AChE active site favors the $R$-enantiomer.

\subsection{STD-NMR study of the AChE- (rac)-1 interaction}

STD-NMR is a well-known physico-chemical technique that allows one to study protein-ligand interactions in a quantitative manner, it allows one to deduce the proximity of key regions (including functional groups) of the ligand with the protein active site. ${ }^{17,18}$ ( $\mathrm{rac}$ )-1 was used for this study.

This method was used to validate the results obtained in the molecular docking studies discussed above. In the case of AChE (eel) the following results were obtained (Fig. 5). H19 presented a 100\% attenuation and the piperidine ring a 65\% STD- attenuation, probably due to $\mathrm{CH}-\pi$ interaction with Trp86. This was previously simulated in the case of $(R)-1$ with a predicted bond distance of $2.98 \AA$ between the piperidine ring's protonated amine and Trp86. The phenyl ring showed a $47 \%-59 \%$ attenuation, probably due to $\pi-\pi$ stacking with Tyr 341 as was simulated above in the case of $(S)-1$. The fused benzene ring of the oxindole core, showed attenuations in the range $55-59 \%$, which supports a $\pi-\pi$ interaction between this unit and Tyr341 in the case of the $(R)$-enantiomer.

Very different results were obtained, upon conducting the same study with BuChE (see Fig. 6). The phenyl group protons presented an STD-attenuation of $74 \%-100 \%$, probably due to $\pi-\pi$ stacking with Trp82 as was simulated for both $(S)-\mathbf{1}$ and $(R)-\mathbf{1}$. In the case of the fused benzene protons of the oxindole core an STD-attenuation of between $79 \%$ and $100 \%$ was observed, which supports $\pi-\pi$ stacking with Tyr332 in the case of $(S)-1$ (Fig. 6).

It should be noted that a very similar result has previously been observed for the STD-NMR study of ( $r a c)-3$ with eqBuChE, the fused benzene oxindole ring presented attenuations in the range $55-100 \%$, the methylene unit of the benzyl group an attenuation of $20 \%$, and the 3 -phenyl ring assumed an attenuation of $125 \%$, thus further validating this study.

Our STD results would seem to indicate that the interactions between (rac)-1 and BuChE are stronger than with AChE, suggesting a better level of inhibition of BuChE than AChE, which was found to be indeed the case (the $\mathrm{IC}_{50}$ was $18.26 \mu \mathrm{M}$ ).

\subsection{Brine shrimp toxicity evaluation}

Results show that (rac)-1 presented $5 \%$ of mortality at a concentration of $1000 \mu \mathrm{g} \mathrm{mL}^{-1}(3.10 \mathrm{mM})$ and the commercial standard, donepezil, presented $26 \%$ mortality for $1000 \mu \mathrm{g} \mathrm{mL}{ }^{-1}$ (2.64 mM). No mortality was observed with the negative controls, with and without 
A

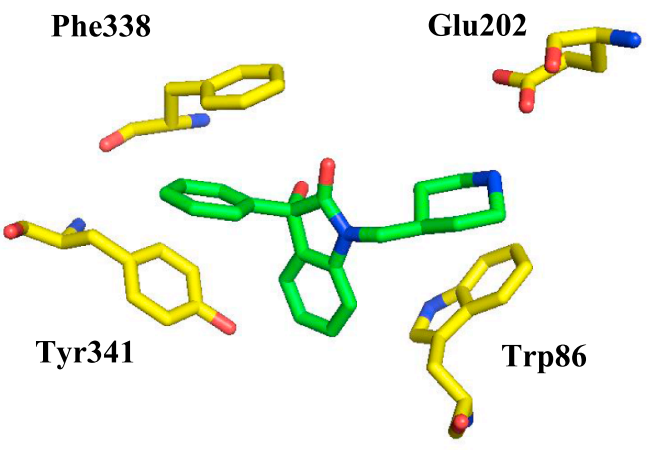

C

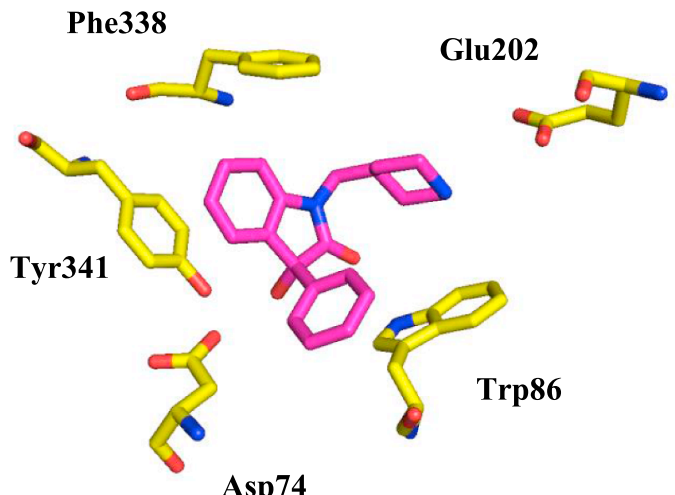

$\mathbf{E}$

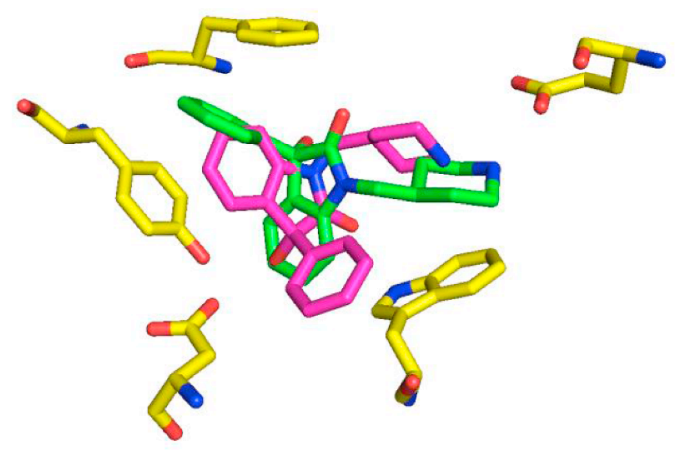

B

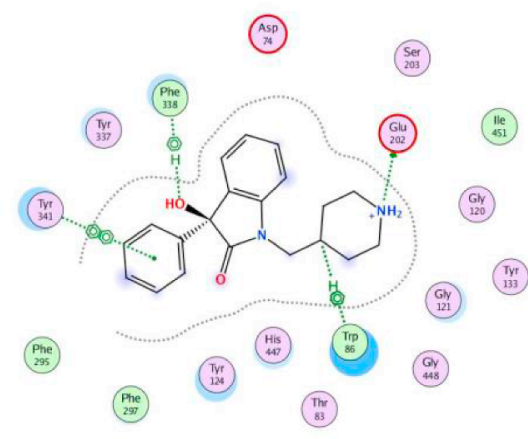

D

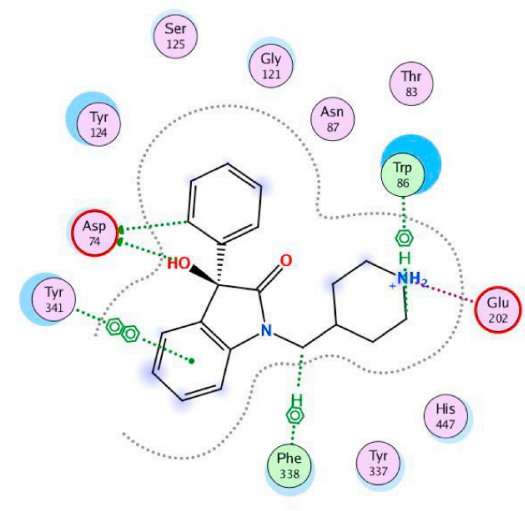

(3ai)

F

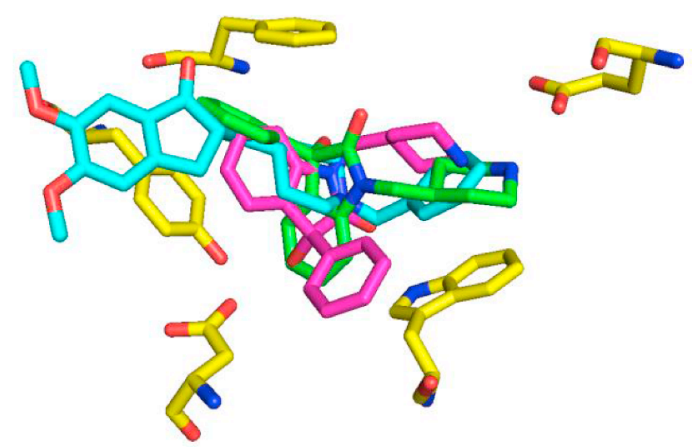

Fig. 3. Compound $(S)$-1 (green) interaction with $h A C h E$ (PDB 4EY7) residues in the binding pocket. (A) Binding mode and residues interacting in the binding pocket and (B) Interactions diagram; Compound (R)-1 (violet) interaction with hAChE (PDB 4EY7). (C) Binding mode and residues interacting in the binding pocket and (D) Interactions diagram, (E) Superimposed poses of compounds $(S)-1$ and $(R)-1$; (F) Superimposed poses of compounds $(S)$-1, $(R)-1$, and donepezil (cyan) (generated with MOE 2016.08 and PyMol). The key binding site residues are displayed.

DMSO and when potassium dichromate $\left(\mathrm{K}_{2} \mathrm{Cr}_{2} \mathrm{O}_{7}\right)$ was used as a positive control, with a concentration of $100 \mu \mathrm{g} \mathrm{mL}^{-1}(0.34 \mathrm{mM})$ the mortality rose to $100 \%$. The dose-response curve for potassium dichromate showed an $\mathrm{LC}_{50}$ value of $15.04 \mu \mathrm{g} \mathrm{mL}^{-1}(0.05 \mathrm{mM})$. On the other hand (rac)-1 presented a mortality of only $5 \%$ lethality at a concentration of $3.10 \mathrm{mM}$ as opposed to a mortality of $26 \%$ at a $2.64 \mathrm{mM}$ concentration in the case of donepezil.

\subsection{Acute toxicity evaluation of cholinesterase inhibitors}

Acute toxicity of (rac)-1 was evaluated in swiss albino mice and the
$\mathrm{LD}_{50}$ was determined according to the Up and Down procedure. ${ }^{19}$ The estimated $\mathrm{LD}_{50}$ was aprox. $100 \mathrm{mg} \mathrm{kg}^{-1}$. The $\mathrm{LD}_{50}$ of donepezil for intravenous administration reported in the literature was $3.7 \mathrm{mg} \mathrm{kg}^{-1} .^{20}$ On comparing these results, $(\mathrm{rac})-1$ presented an $\mathrm{LD}_{50}$ higher than donepezil, suggesting that our compound is less toxic than donepezil.

\subsection{Ex vivo pharmacological evaluation}

The activity of AChE in the brain was measured in the presence of donepezil hydrochloride, that showed an $\mathrm{IC}_{50}$ of $1.06 \pm 0.29 \mu \mathrm{M}$ (Fig. 7) and in the presence of (rac)-1, which gave $28 \%$ inhibition at the 
A

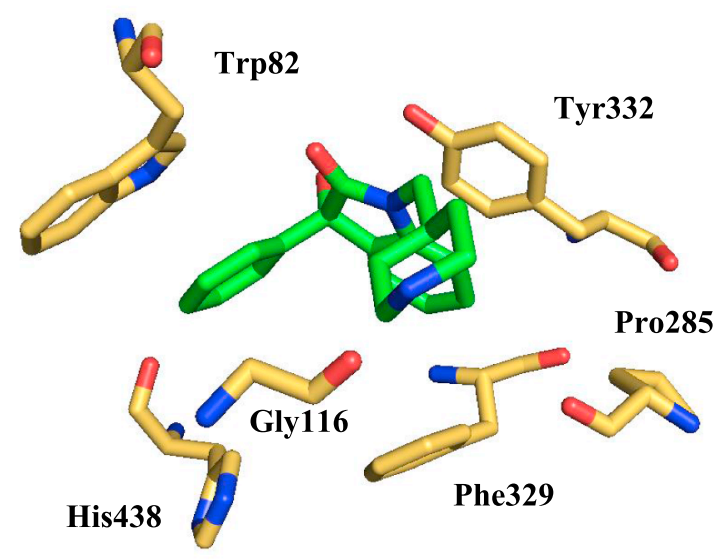

B
C

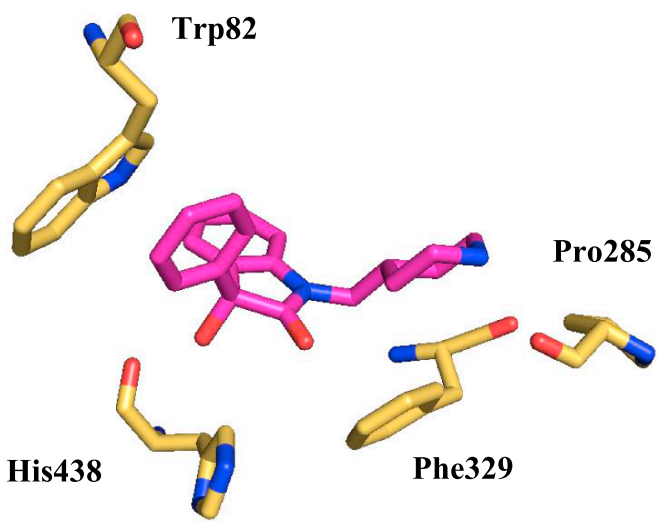

Gils

(iii)

(Tip

(Aas)

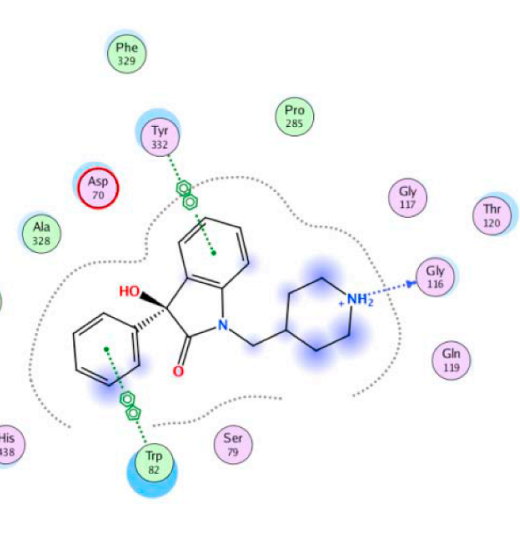

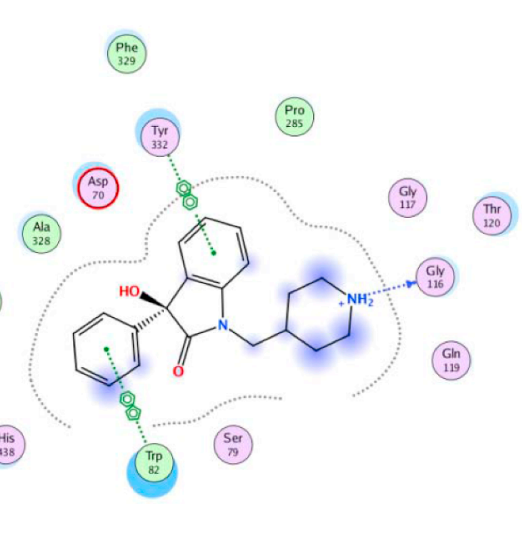

(18)

D

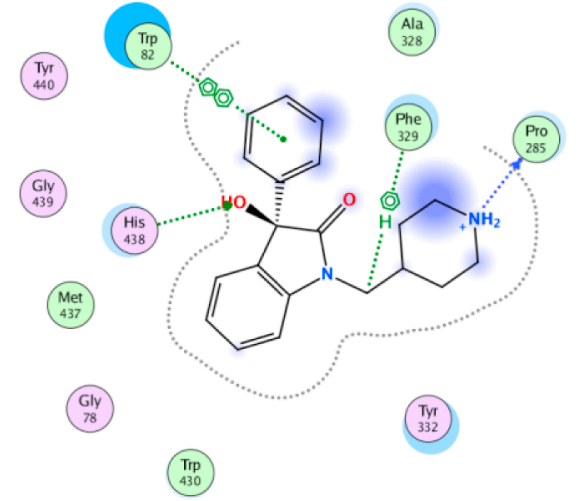

$\mathbf{F}$

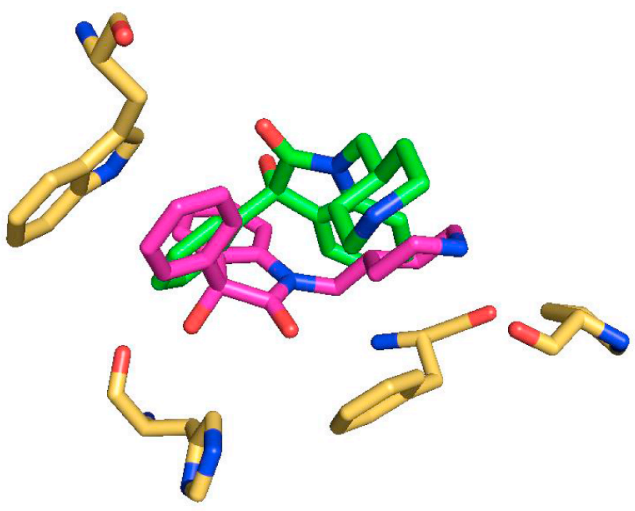

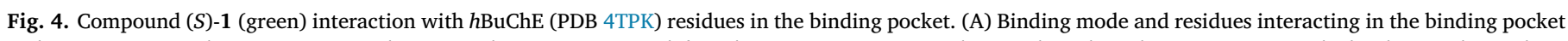

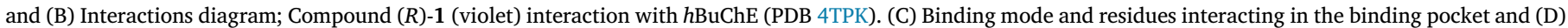
Interactions diagram; (generated with MOE 2016.08 and PyMol). The key binding site residues are displayed.

highest concentration tested $(1.5 \mathrm{mM})$. Donepezil had the lower $\mathrm{IC}_{50}$.

(rac)-1 and donepezil were also tested in the mouse liver (Figs. 8 and 9). Donepezil showed no selectivity, inhibiting both enzymes, AChE and BuChE with $\mathrm{IC}_{50}$ values of $125.31 \pm 1.19$ and $147.23 \pm 1.16 \mu \mathrm{M}$, respectively.

(rac)-1 was also tested for AChE and BuChE inhibition (Fig. 9) and it proved to be a better inhibitor of BuChE than of AChE. However, by comparing these results with those obtained for donepezil in Fig. 8, we realized that $(\mathrm{rac})-\mathbf{1}$ showed higher $\mathrm{IC}_{50}$ values with either $\mathrm{AChE}$ or BuChE.

In terms of pharmacokinetics, donepezil is metabolized by CYP 450 isoenzymes 2D6 and 3A4 and is excreted intact in the urine and extensively metabolized to four major metabolites, two of which are known to be active, as well as a number of minor metabolites, not all of which have been identified. Due to the similarity of our compound structure with that of donepezil it is possible that ( $\mathrm{rac})-\mathbf{1}$ has a similar 

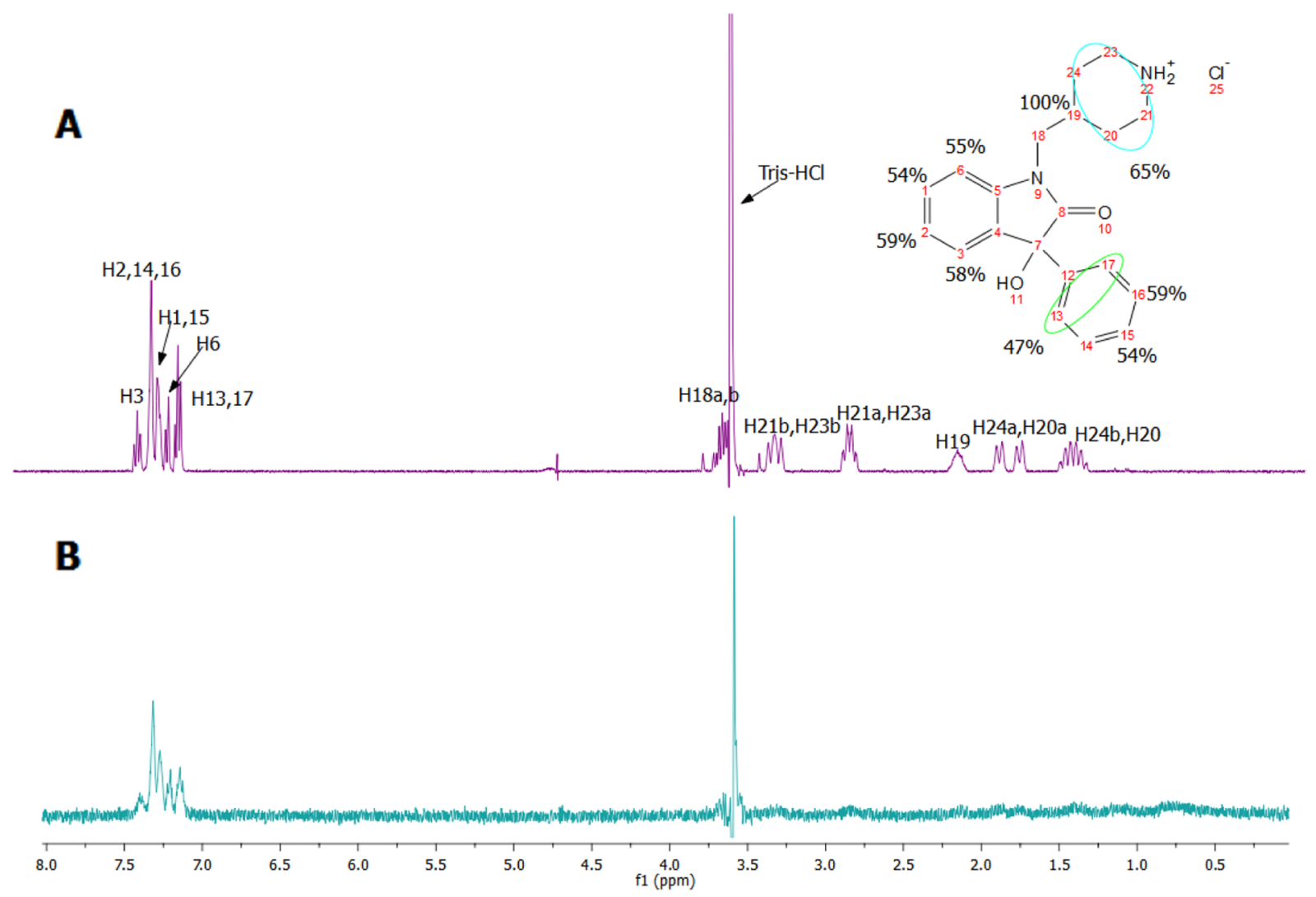

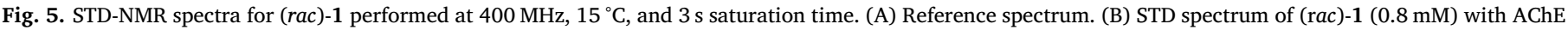

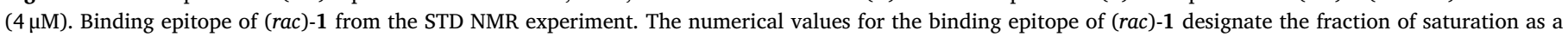
percentage, between the ligand protons and the protein active site, normalized to the maximum ligand STD attenuated signal (H19; $100 \%$ ).

pharmacokinetic profile to donepezil. ${ }^{21}$

\subsection{In vivo pharmacological evaluation}

Both donepezil hydrochloride and (rac)-1 decreased AChE activity in the brain, with values significantly different from the control ( $\mathrm{p}<0.05$ ) (Fig. 10). Interestingly, (rac)-1 presented a better AChE inhibition than donepezil, although the results were not significantly different ( $\mathrm{p}>0.05)$. AChE activity in the brain of swiss mice after the administration of $3 \mathrm{mg} / \mathrm{Kg}$ of (rac)-1 was $0.096 \mu \mathrm{mol} . \mathrm{min}^{-1} \cdot \mathrm{mg}^{-1}$ while for donepezil it was $0.112 \mu \mathrm{mol} \cdot \mathrm{min}^{-1} \cdot \mathrm{mg}^{-1}$.

Donepezil is a selective, reversible and noncompetitive inhibitor of $\mathrm{AChE}$ in vitro and relatively selective for brain AChE in vivo. ${ }^{22}$

It was possible to determine both AChE and BuChE activity in the liver (Fig. 11). Donepezil and (rac)-1 didn't present significantly different values to each other, suggesting no relevant inhibition of both cholinesterases in the liver. On the other hand, the $3 \mathrm{mg} \mathrm{kg}^{-1}$ administration of both donepezil and (rac)-1 presented the same level of inhibition for liver BuChE. As the molecular weight of donepezil $(415.96 \mathrm{~g} / \mathrm{mol})$ is similar to the molecular weight of $(\mathrm{rac})-\mathbf{1}(358.87 \mathrm{~g} /$ mol), the same doses of both compounds are almost equivalent to equimolar doses. At the same time, by measuring the corresponding brain AChE inhibition level we could obtain crucial information on the comparison of the effect of (rac)-1 on AChE with that of the standard donepezil. The two concentrations of ( $\mathrm{rac}$ )-1 tested decreased AChE activity in the brain by the same percentage, showing no overall benefits in the administration of a dose higher than $3 \mathrm{mg} \mathrm{kg}^{-1}$. With regards to BuChE activity in the brain, no useful results were obtained since it was not possible to quantify this enzyme's activity in the brain of our healthy mouse model. ${ }^{23,24}$

\section{Conclusions}

The overall aim of this study was to determine the pharmacological properties of (rac)-1 in a mouse model and determine its potential for use as an alternative ChE inhibitor for the treatment of AD.

(rac)-1 was chosen due to its favorable water solubility properties compared to analogues with better enzyme binding values. Preliminary molecular docking studies were conducted with both $(R)$ and $(S)-1$ with $h \mathrm{AChE}$ and $h \mathrm{BuChE}$, prior to advancing to the mouse model, and indeed favorable interactions were observed, with $(R)$-1 showing the best binding with AChE and (S)-1 with BuChE. STD-NMR studies were used to successfully validate these results.

Both (rac)-1 and donepezil presented low toxicity against Artemia salina $\left(\mathrm{LC}_{50}>1000 \mu \mathrm{g} \mathrm{mL}{ }^{-1}\right.$ ), with (rac)-1 being the less toxic of the two.

Gratifyingly it was found that ( $\mathrm{rac}$ )-1 presented a slightly better inhibition of AChE than donepezil in the mouse brain and the same level of inhibition for mouse liver BuChE as donepezil.

\section{Experimental section}

\subsection{Chemicals}

All reagents were obtained from Sigma-Aldrich. rac-4-((3-hydroxy2-oxo-3-phenylindolin-1-yl) methyl) piperidin-1-ium chloride was synthesized as previously described. ${ }^{10}$ AChE used in the STD-NMR assays was from Electrophorus eletricus (VI-S lyophilized powder, $814 \mathrm{U} \mathrm{mg}^{-1}$ protein), BuChE used in the STD-NMR assays was from equine serum (lyophilized powder, $1830 \mathrm{U} \mathrm{mg}^{-1}$ protein). The lyophilized enzymes were prepared in $20 \mathrm{mM}$ Tris- $\mathrm{HCl} \mathrm{D}_{2} \mathrm{O} \mathrm{pH} 7.6$ buffer. Donepezil hydrochloride solution was prepared in DMSO- $d_{6}$ and ( $\mathrm{rac}$ )-1 solution was 
A

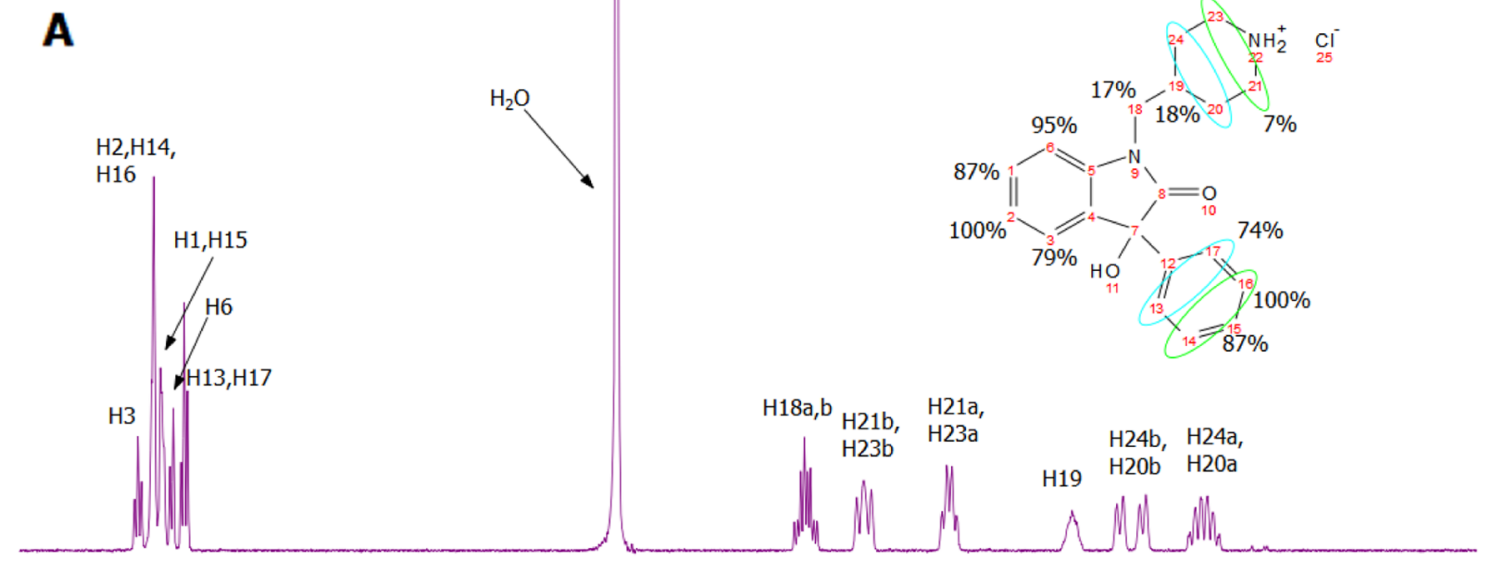

B

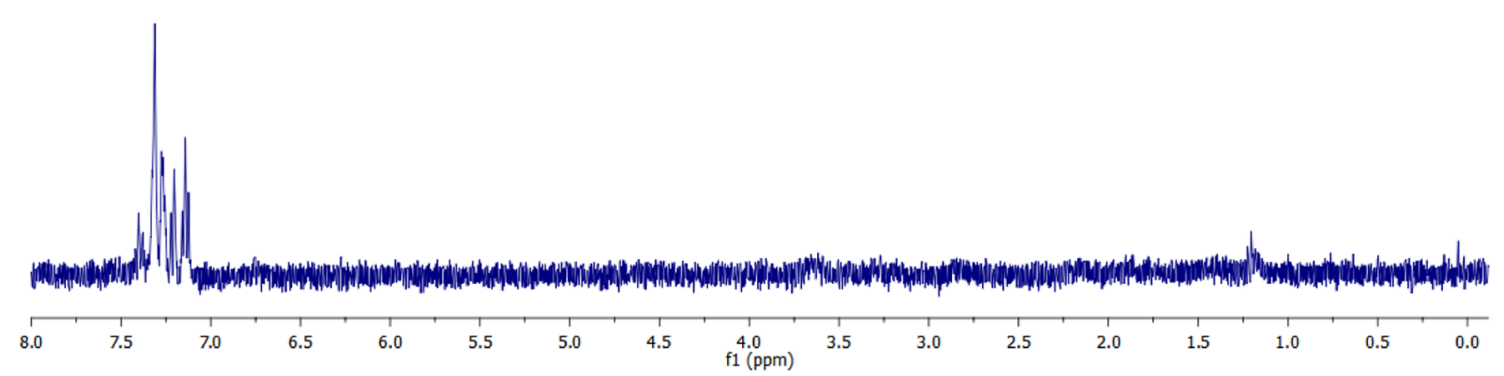

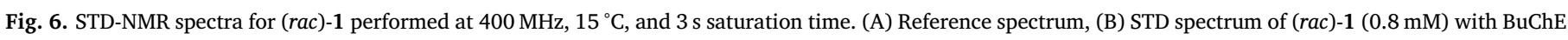

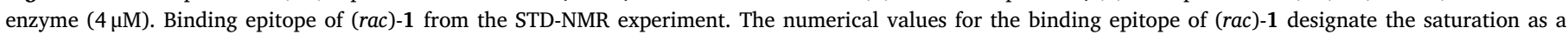
percentage, between the ligand protons and the protein active site, normalized to the maximum ligand STD signal (H2, H14, H16; 100\%).

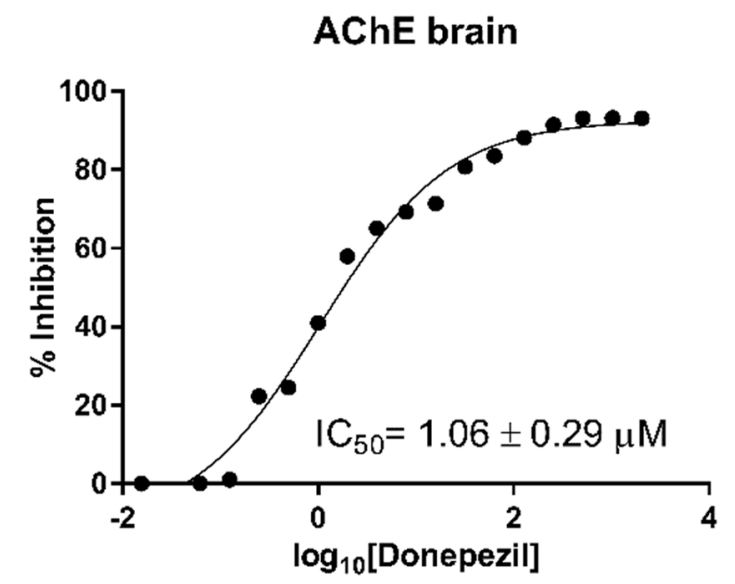

Fig. 7. Dose-response relation of AChE in the brain of Swiss mice in the presence of donepezil.

prepared in $\mathrm{D}_{2} \mathrm{O}$ to the desired concentrations. Compounds used in the A. salina assay were prepared in a saline solution. Compounds used in the animal acute toxicity assay, were prepared in distilled water. Compounds used in the in vivo animal assay were prepared in distilled water and in the ex vivo animal assay were prepared in phosphate buffer.

\subsection{Synthesis of (rac)-1}

This compound was synthesized according to our previous method. ${ }^{10}$

${ }^{1} \mathrm{H}$ NMR (DMSO- $\left.d_{6}, 400 \mathrm{MHz}\right){ }^{1} \mathrm{H}$ NMR $\left(\mathrm{CDCl}_{3}, 400 \mathrm{MHz}\right) \delta: 9.00$ (sbroad, 1H), 8.75 (sbroad, 1H), $7.37-7.25(\mathrm{~m}, 5 \mathrm{H}), 7.16(\mathrm{t}, 2 \mathrm{H}$,
$J=7.3 \mathrm{~Hz}$ ), 7.05 (t, $1 \mathrm{H}, J=7.4 \mathrm{~Hz}), 6.75$ (s, $1 \mathrm{H}), 3.66-3.53(\mathrm{~m}, 2 \mathrm{H})$, $3.26-3.20$ (m, $2 \mathrm{H}), 2.82-2.79(\mathrm{~m}, 2 \mathrm{H}), 2.10-2.05(\mathrm{~m}, 1 \mathrm{H}), 1.85-$ $1.72(\mathrm{~m}, 2 \mathrm{H}), 1.49-1.35(\mathrm{~m}, 2 \mathrm{H}) \mathrm{ppm}$.

${ }^{13} \mathrm{C}$ NMR (DMSO- $\left.d_{6}, 400 \mathrm{MHz}\right) \delta: 177.1,142.9,141.3,133.1,129.4$, 128.2, 127.6, 125.5, 124.6, 122.8, 109.3, 76.9, 44.2, 42.6, 42.5, 31.9, 26.2, $26.1 \mathrm{ppm}$.

\subsection{Docking studies}

Docking studies were conducted by designing both enantiomers of compound 1, namely $(S)-\mathbf{1}$ and $(R)-\mathbf{1}$. Both the enantiomers were studied in their protonated forms, due to the physiological $\mathrm{pH}$ of the cell. The structures of these compounds were built, and their energy minimized using the MMF94x forcefield, within the Molecular Operating Environment (MOE) version 2016.08 ${ }^{14}$. To prepare the enzymes for the molecular docking studies, the co-crystallized inhibitors as well as all the crystallographic waters included in the PDB structure, were removed. Hydrogen atoms were then added and the protonation states were correctly assigned using the Protonate-3D tool within the Molecular Operating Environment (MOE) 2016.08 software package.

The molecular docking simulations were performed, using GOLD software version 5.2.0 $0^{25}$ and carried out in the PDB structures 4EY7 (human AChE) ${ }^{26}$ and 4TPK (human BuChE) ${ }^{27}$ downloaded from Protein Data Bank.

For each compound, 1000 docking runs were performed. Each conformation was ranked according to its scores, GoldScore scoring function scores were rescored with ChemPLP scoring function. For each ligand structure, the top 3 solutions were visually inspected and critically evaluated. For both structures (4EY7 and 4TPK) the docking protocol (number of runs, binding site center, presence of waters in the active site, radius) were validated using the crystallographic ligands and their poses were able to reproduce the positions of the respective 


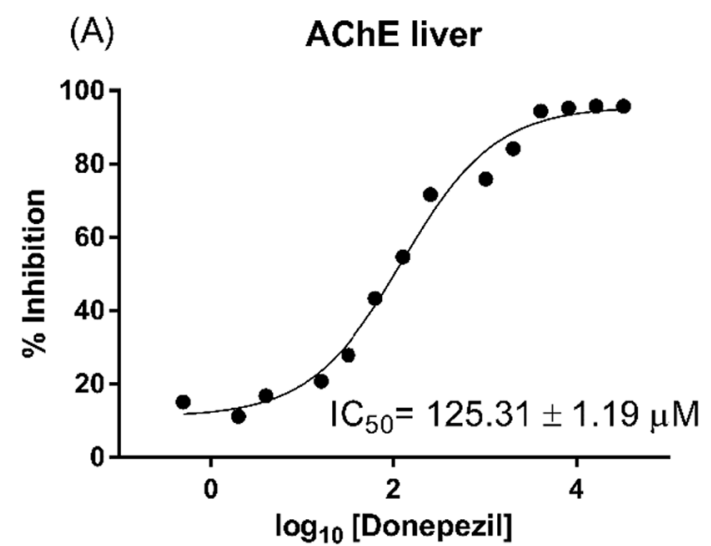

(B) BuChE liver

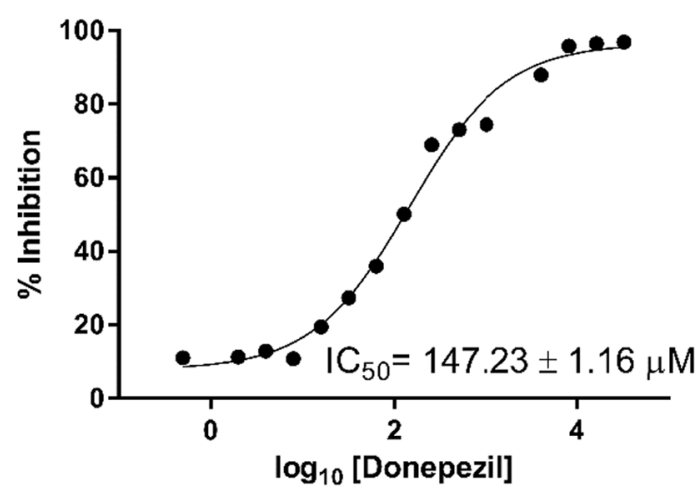

Fig. 8. Dose-response relation of (A) AChE and (B) BuChE in the liver of Swiss mice, in the presence of donepezil.

crystallographic ligands with a root-mean-square deviation (RMSD) lower than $1 \AA$.

\subsection{STD-NMR experiments}

The NMR spectroscopy experiments were performed on a Bruker Avance III $400 \mathrm{MHz}$ spectrometer equipped with a $5 \mathrm{~mm}$ broadband (PABBO BB/19F-1H/D Z-GRD) resonance probe head. STD NMR experiments were carried out with solvent suppression and a $10 \mathrm{~ms}$ spinlock filter after the $90^{\circ}$ pulse to reduce residual signals from the protein. For selective saturation, cascades of Gaussian pulses with a length of $50 \mathrm{~ms}$ and $40-60 \mathrm{~dB}$ of attenuation were employed, with an interpulse delay of $1 \mathrm{~ms} .^{28,29}$ The on-resonance and off-resonance frequencies were set to 0 and $12000 \mathrm{~Hz}$, respectively. STD-NMR controls were performed using the ligand itself. Blank experiments were performed to guarantee the absence of direct saturation of the ligand proton signals. The relaxation delay was properly adjusted so that the experiment time length was kept constant at $6.5 \mathrm{~s}$. Water suppression at $1880 \mathrm{~Hz}$ (4.7 ppm) was conducted. A sweep-width of $8012.82 \mathrm{~Hz}(20.03 \mathrm{ppm})$ was employed. Specifically, the saturation time to obtain the STD buildup curves were recorded at $0.25,0.5,1,2,3,4$, and $5 \mathrm{~s} .{ }^{17,18}$

A $5 \mu \mathrm{M}$ eqBuChE (equine) or eeAChE (Electrophorus electricus (eel)) solution was prepared in a Tris- $\mathrm{HCl}$ buffer in $99.9 \% \mathrm{D}_{2} \mathrm{O}(20 \mathrm{mM}$ at $\mathrm{pH}$ 7.4). A $5 \mathrm{mM}$ stock solution was prepared for each compound (ligand). Samples for NMR analysis were prepared by adding $100 \mu \mathrm{L}$ of the ligand to a $500 \mu \mathrm{L}$ of enzyme solution.

\subsection{Brine shrimp toxicity assay}

The toxicity of standard and sample solutions was evaluated using the A. salina L. lethality bioassay in order to determine the lethal

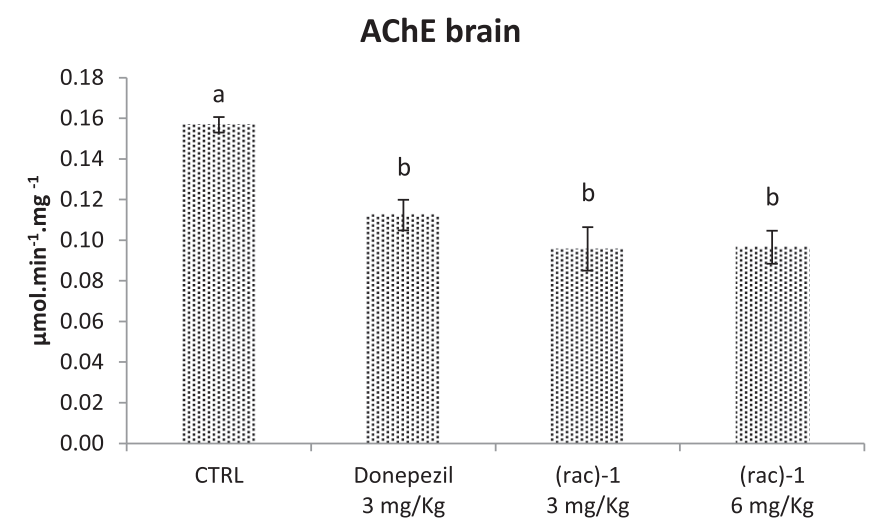

Fig. 10. In vivo AChE activity in the brain of swiss mice, in the presence of donepezil and $(\mathrm{rac})-\mathbf{1}$. Different letters represent values significantly different $(\mathrm{p}<0.05)$.

concentration that correspond to $50 \%$ dead larvae $\left(\mathrm{LC}_{50}\right) .^{30}$ The procedure was performed according to the Artoxkit $M$ protocol (MicroBioTests, Inc. $)^{31}$ In a multiwell test plate, $100 \mu \mathrm{L}$ of each solution was added to $900 \mu \mathrm{L}$ of a saline medium and 10 larvae were added to each well. Assays were repeated nine times for each concentration. Plates were observed after $24 \mathrm{~h}$ of incubation, at $25^{\circ} \mathrm{C}$, using a Research Stereomicroscope System (Olympus SZX9) and dead nauplii counted. $\mathrm{LC}_{50}$ values were determined using GraphPad Prism $5^{\mathrm{TM}}$ software. Potassium dichromate was used as a positive control $\left(3.125 \mu \mathrm{gL}^{-1}\right.$ to $150 \mu \mathrm{g} \mathrm{mL}^{-1}$ ). Two negative controls were prepared with a saline medium without DMSO and with 5\% DMSO.
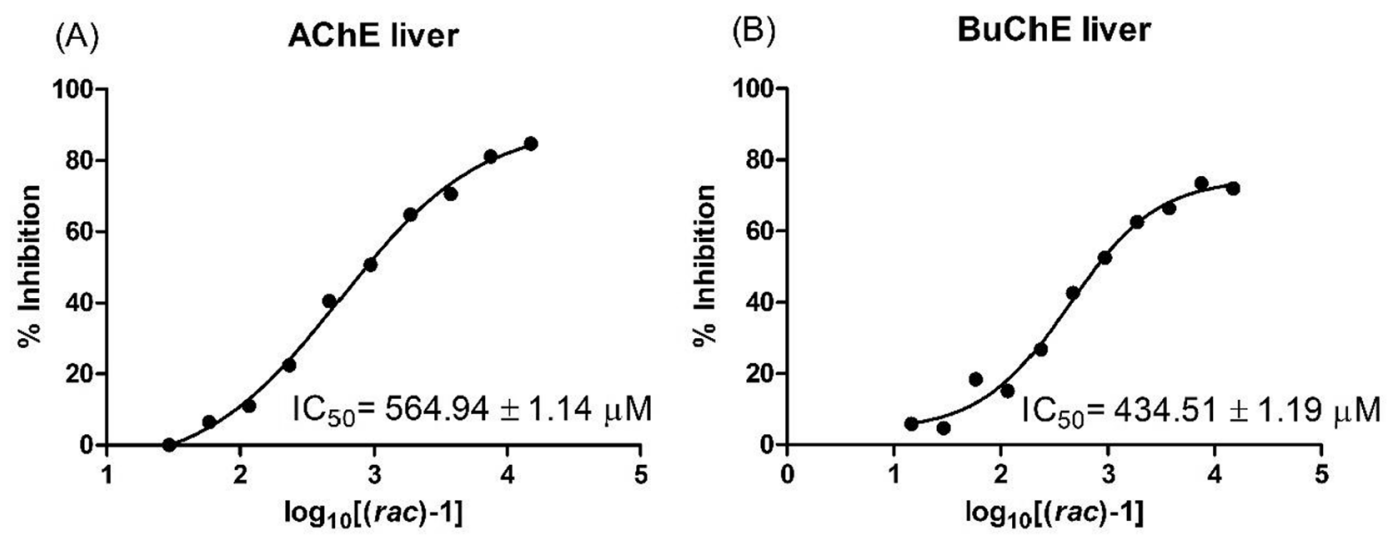

Fig. 9. Dose-response relation of $\mathrm{AChE}$ and $\mathrm{BuChE}$ in the liver of swiss mice, in the presence of (rac)-1. 


\section{Liver}

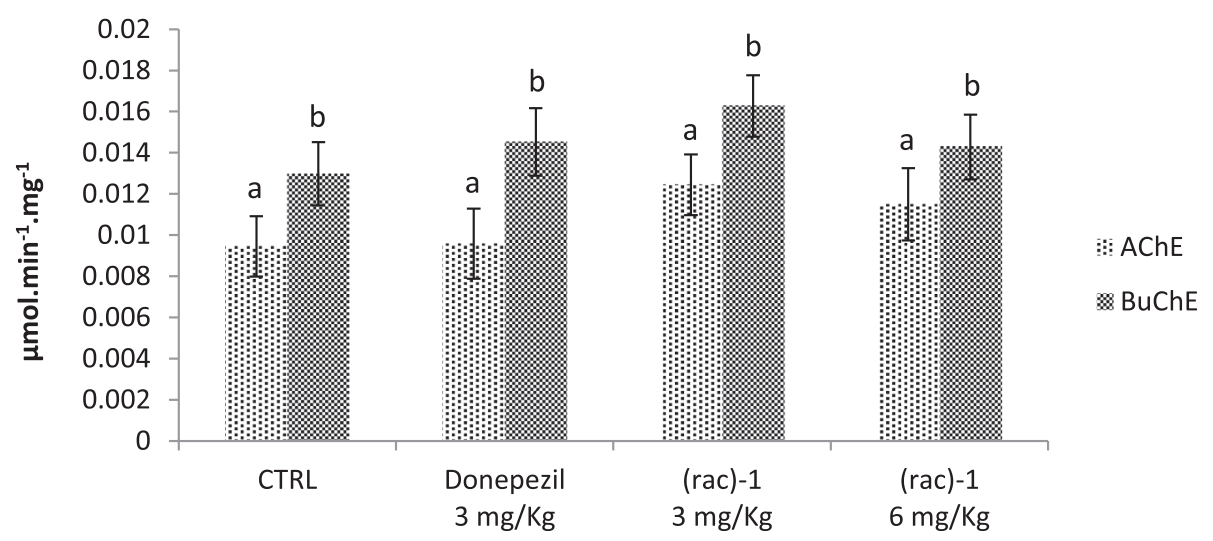

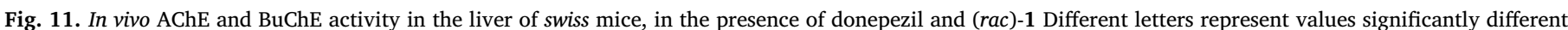
$(p<0.05)$ to each enzymatic activity.

\subsection{Animals}

The acute toxicity study and the pharmacological evaluation were carried out using 8 weeks old male Swiss albino mice (Mus musculus), weighting $23 \pm 1 \mathrm{~g}$. The organs (brain and liver) used to determine the $\mathrm{IC}_{50}$ values were obtained from Swiss mice. All animals were housed in a controlled environment ( $12 \mathrm{~h}$ light/dark cycles, $\left.23 \pm 1{ }^{\circ} \mathrm{C}\right)$ with food and water ad libitum. Food was withheld $16 \mathrm{~h}$ before the experiments. Procedures were conducted in accordance with the National Institutes of Health Guide for Care and Use of Laboratory Animals Guidelines and European Community Guidelines. ${ }^{32}$ All procedures involving animals were approved by the Ethics Committee. ${ }^{33}$

\subsection{Preparation of animals}

\subsubsection{Acute intraperitoneal toxicity evaluation}

Acute toxicity of ( $\mathrm{rac}$ )-1 was evaluated in swiss albino mice and the $\mathrm{LD}_{50}$ was determined according to the OECD Up-and-Down procedure. ${ }^{19}$

The animals were divided into two groups of 3 mice each. The compound administration was by intraperitoneal (i.p.) injection in the upper left quadrant of the animal's abdomen. The animals were kept in observation for 15 days, during which they were housed in a controlled environment ( $12 \mathrm{~h} \mathrm{light/dark}$ cycles, $23 \pm 1{ }^{\circ} \mathrm{C}$ ) with food and water ad libitum.

\subsubsection{Ex vivo pharmacological evaluation}

Animals were sacrificed by decapitation, and brains and livers were dissected out, washed in ice-cold potassium phosphate buffer $(0.2 \mathrm{M}$, $\mathrm{pH}$ 7.6), and homogenized. The brain homogenate was prepared in potassium phosphate buffer $0.1 \mathrm{M}$, pH $7.6(1: 10, \mathrm{w} / \mathrm{v})$, and then centrifuged at $10,000 \mathrm{~g}$ and $4{ }^{\circ} \mathrm{C}$ for $10 \mathrm{~min}$. The liver homogenate was prepared in potassium phosphate buffer $0.1 \mathrm{M}, \mathrm{pH} 7.6(1: 10, \mathrm{w} / \mathrm{v})$, and then centrifuged at $1000 \mathrm{~g}$ and $4{ }^{\circ} \mathrm{C}$ for $15 \mathrm{~min}$.

Donepezil hydrochloride and ( $\mathrm{rac}$ )-1 were prepared in potassium phosphate buffer (0.2 M, pH 7.6), and were tested against AChE activity in the brain and both AChE and BuChE activity in the liver.

AChE and BuChE activity was determined following a modified Ellman's method, ${ }^{34}$ and the $\mathrm{IC}_{50}$ values were calculated.

Total protein quantification followed the Lowry method. ${ }^{35}$

\subsubsection{In vivo pharmacological evaluation}

The animals were divided into four groups of six animals. The compounds administration was by intraperitoneal (i.p.) injection in the upper left quadrant of the animal's abdomen. Group I was administered with the vehicle (distilled water), group II was administered with $3 \mathrm{mg} \mathrm{kg}^{-1}$ of donepezil hydrochloride, group III was administered with $3 \mathrm{mg} \mathrm{kg}^{-1}$ of (rac)-1 and group IV was administered with $6 \mathrm{mg} \mathrm{kg}^{-1}$ of (rac)-1.

Animals were sacrificed by decapitation, $1 \mathrm{~h}$ after i.p. injection, and brains and livers were dissected out, washed in ice-cold potassium phosphate buffer $(0.2 \mathrm{M}, \mathrm{pH} 7.6)$, and homogenized. The brain homogenate was prepared in potassium phosphate buffer $0.1 \mathrm{M}, \mathrm{pH} 7.6$ $(1: 10, \mathrm{w} / \mathrm{v})$, and then centrifuged at $10,000 \mathrm{~g}$ and $4{ }^{\circ} \mathrm{C}$ for $10 \mathrm{~min}$. The liver homogenate was prepared in potassium phosphate buffer $0.1 \mathrm{M}$, $\mathrm{pH} 7.6(1: 10, \mathrm{w} / \mathrm{v})$, and then centrifuged at $1000 \mathrm{~g}$ and $4{ }^{\circ} \mathrm{C}$ for $15 \mathrm{~min}$.

$\mathrm{AChE}$ and BuChE activities were determined following a modified Ellman's method, ${ }^{34}$ and the $\mathrm{IC}_{50}$ values were calculated.

Total protein quantification followed the Lowry method. ${ }^{35}$

\subsection{Statistical analysis}

All data was expressed as mean \pm standard deviation of triplicate measurements. Statistical analysis of data was performed using oneway ANOVA. A probability value of $p<0.05$ was considered statistically significant. Multiple comparisons of means were analyzed using the b-Tukey test. Analyses were performed using SPSS ${ }^{\circledR} 22$ Windows, IBM. The dose-response curve and the $\mathrm{LC}_{50}$ values, as well as the $\mathrm{IC}_{50}$ for all the samples were determined with the software GraphPad Prism $5^{\mathrm{TM}}$.

\section{Acknowledgements}

The authors gratefully acknowledge the following funding sources: the INMOLFARM - Molecular Innovation and Drug Discovery (ALENT57-2011-20) of the FEDER-INALENTEJO program ALENT-07-0224FEDER-001743, and for a grant to PB. We are grateful to the Fundação para a Ciência e a Tecnologia (FCT) for funding through the strategic project PEst-OE/QUI/UI0619/2016.

\section{Conflicts of interest statement}

There were no conflicts of interest.

\section{Appendix A. Supplementary data}

Supplementary data to this article can be found online at https:// doi.org/10.1016/j.bmc.2018.12.007. 


\section{References}

1. Hargreaves RJ. ACS Med Chem Lett. 2012;3:862

2. Selkoe DJ. Science. 2012;337:1488

3. Price D. Annu Rev Neurosci. 1986;9:489.

4. Garcia-Ayllon M, Small D, Avilla J, Sáez-Valero J. Front Mol Neurosci. 2011;4:1.

5. Francis PT, Palmer AM, Snape M, Wilcock GK. J Neurol Neurosurg Psychiatry. 1999;66:137.

6. Ingkaninan $\mathrm{K}$, de Best C, Irth H, et al. J Chromatogr A. 2000;872:61.

7. Ingkaninan $\mathrm{K}$, Temkitthawon $\mathrm{P}$, Chuenchom K, Yuyaem T, Thongnoi W. J Ethnopharmacol. 2003;89:261.

8. Singh MK, Kukreja H, Chugh R, Silakari O, Singh D. Eur J Med Chem. 2013;70:165

9. Kaur M, Singh M, Chadha N, Silakari O. Eur J Med Chem. 2016;123:858.

10. Totobenazara J, Bacalhau P, San Juan A, et al. Chem Select. 2016;1:3580.

11. Ertl P, Rohde B, Selzer P. J Med Chem. 2000;43:3714.

12. Hou TJ, Xia K, Zhang W, et al. Chem Inf Comput Sci. 2004;44:266.

13. Labute, P., MOE LogP Model, 1998, unpublished.

14. Molecular Operating Environment (MOE), 2013.08; Chemical Computing Group ULC, Montreal, Canada, 2018.

15. Hansch C, Leo AJ. Substituent Constant for Correlation Analysis in Chemistry and Biology. New York: Wiley; 1979.

16. Bacalhau P, San Juan A, Goth A, Caldeira AT, Martins R, Burke A. J Bioorg Chem. 2016;67:105.

17. Angulo J, Nieto PM. Eur Biophys J. 2011;40:1357.

18. Meyer B, Peters T. Angew Chem Int Ed. 2003;42:864.

19. OECD Guideline for testing of chemicals: Acute oral toxicity - Up-and-down procedure. Environmental Health and Safety Monograph Series on Testing and Assessments $\mathrm{n}^{\circ}$ 425. In Book OECD Guideline for testing of chemicals: Acute oral toxicity - Up-anddown procedure. Environmental Health and Safety Monograph Series on Testing and Assessments $n^{\circ}$ 425. 2001.

20. http://www.pfizer.com/sites/default/files/products/material_safety_data/ Donepezil_HCl FCT 05-Oct-2015.pdf.

21. Shigeta M, Homma A. CNS Drug Rev. 2001;7:353.

22. Sugimoto H, Ogura H, Arai Y, Iimura Y, Yamanishi Y. Jpn J Pharmacol. 2002;89:7.

23. Cutler NRP, Sramek JJ. Acta Neurol Scand. 1998;97:244.

24. Ballard CG. Eur Neurol. 2002;47:64.

25. Jones G, Willett P, Glen RC, Leach AR, Taylor R. J Mol Biol. 1997;267:727.

26. Cheung J, Rudolph MJ, Burshteyn F, et al. J Med Chem. 2012;55:10282.

27. Brus B, Kosak U, Turk S, et al. J Med Chem. 2014;57:8167.

28. Mayer M, Meyer B. Angew Chem Int Ed. 1999;38:1784.

29. Berger, S., Braun, S.: 200 and More NMR Experiments - A Practical Course. 2014

30. Hodgson E, Levi PE. A Textbook of Modern Toxicology. Appleton Lange. 1997.

31. http://www.microbiotests.be/SOPs/Artoxkit\%20M\%20SOP\%20-\%20A5.pdf.

32. Council Directive 86, 609, EEC of 24, on the approximation of laws, regulations and administrative provisions of the Member States regarding the protection of animals used for experimental and other scientific purposes E.C. Guidelines National Institute of Health November 1986 Brussels, Belgium European Economic Community 1986.

33. All procedures involving animals were supervised by a research worker accredited by FELASA no. 020/08 (Federation of European Laboratory Animal Science Association) Hau J, Schapiro SJ. Handbook of Laboratory Animal Science, Second Edition: Animal Models. 2nd edn: New York: CRC Press; 2003.

34. Ellman G, Courtney K, Andres V, Featherstone R. Biochem Pharmacol. 1961;7:88.

35. Lowry OH, Rosebrough NJ, Farr AL, Randall RJ. J Biol Chem. 1951;193:265. 